NASA Technical Meworendum 83340

AIAA-83-0026

\title{
Experimental Comparison of Icing Cloud Instruments
}

(UISA-TH-83340) EXFERTENTAL CCEEATSCI CP ICIUG CICOD IMSTROAEMTS (Uisa) 27 F BC $103 / \mathrm{AF} 101$ CSCI OIf

W. Olsen

Lewis Reseunch Center

Cleveland, Ohio

and

D. Takeuchi

Meteordogy Reseurch, Inc.

Altadena, Colifornia

and

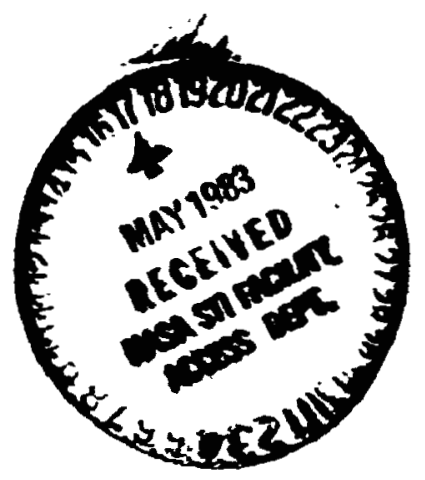

K. Adams

Air Fonce Flight Teat Center

Edwards, California

Prepared for the

Twenty-First Aerospace Sciences Conference

sponsored by the American Institute of

Aeronautics and Astronautics

Reco, Nevada, January 10-13, 1983 


\title{
EXPER IMENTAL COMPARISON OF ICIMG CLOUD INSTRUMENTS
}

\author{
W. $01 \operatorname{sen} t$ \\ National Aeronautics and Space Administration \\ Lewis Research Center \\ Cleveland, Onio $\mathbf{4 4 1 3 5}$
}

and

D. Takeuchi*

Meteorology Research, Inc.

Altadena, California

and

K. Adams

Air Force Flight Test Center

Edwards, California

\section{ABSTRACT}

A number of modern and old-style icing cloud instruments were tested in the spray cloud of the NASA Lewis Icing Research Tunnel (IRT) in order to determine their relative accuracy and their limitations over a broad range of conditions. It was found that the average of the readings from each of the Iiquid water content (LHC) instruments tested agreed closely with each other and with the IRT calibration; but all have a data scatter ( \pm one standard deviation) of about - 20 percent. The effect of this \pm 20 percent uncertainty is probably acceptatle in aero-penalty and deicer experiments. Existing laser spectrometers proved to be too inaccurate for LHC measurements. The error due to water run-off was the same for all ice accretion LWC instruments.

Any given laser spectrometer proved to be $h$ ighly repeatable in its indicattons of volume median drop size (DVM), LHC and drop size distribution. However, there was a significant disagreement between different spectrometers of the same model, even after careful standard cal ibration and data analys is. The scatter about the mean of the DVM data from six Spectrometer Probes tested was $t 30$ percent ( $t$ one standard deviation) and the average was 20 percent higher than the old IRT calibration. The \pm 30 percent uncertainty in OVM can cause an unacceptable variation in the drag coefficient of an airfoil with Ice; however, the variation in a deicer performance test may be acceptable.

The calibrations of ground icing facilities for DVM and LWC should be put on a common basis so that they can be used to calibrate instruments. The laser spectrometer disagreements can possibly be eliminated in flight programs by checking the calibrations with a repeatable portable spray rig. LWC

\footnotetext{
Research Engineer.

" Senfor Scientist.

* Aerospace Engineer.
} 
instruments should all be periodically calibrated in icing tunnels; this additional testing may also improve their reliability.

\section{INTROOUCTION}

The accurate determination of the liquid water content and droplet size of an icing cloud is important information in icing research, ice protection system development and certification testing. In the 1940's and 50's, when the aircraft icing technology was first developed, the instruments used were manually operated (e.g.. listed in ref. 1 are oil slides ind rotating multi-cylinders for drop size, and rotating cylinders and other ice accretion instruments for liquid water content (LHC)). Since that time, a number of modern automated instruments have been developed to measure LHC and drop size. The Rosemount, Leigh, and Johnson and Williams $(J$ and $W$ ) are a few of those used for LHC; while a variety of laser spectroneters have been used for volume mean drop size (DVM) and its distribution.

Even though large numbers of these instruments have been produced and used in countless icing tests and certifications, there have been no comparisons where a large number of different instruments have been compared in the wellbehaved repeatable icing cloud of an icing tunnel. The best comparison for one type of instrument was done at the National Research Council of Canada (MRC). where a large number of $J$ and $W$ LHC instruments were compared in their small icing tunnel (ref. 2). In another experiment, an oil slide and laser hologram were compared (ref. 3); in reference 4, the oil slide and rotating cylinders were compared to a laser spectrometer.

In the test program reported here, a large number of modern and old-style icing cloud instruments were compared in the MASA $6 \times 9$ Foot Icing Research Tunnel (IRT). The instruments tested were for LHC and droplet size (both OWM and distribution). The purposes of the tests were to determine the relative accuracy of these instruments, and their limitations over a broad range of condtitions. The instruments tested are described in the next section.

The comparisor. between the old and modern instruments and with the old IRT calibration will be especially useful because the FAR-25 certification and much of the old icing technology were based on the old instruments and the IRT, whereas modern instruments are used today. This experimental program was jointly sponsored and performed by NASA, the Air Force Flight Test Center and Meteorology Research Inc.

\section{DESCRIPTION OF THE INSTRUMENTS TESTED}

The instruments tested in the IRT are listed below. These instruments are briefly described in this section; more detail can be found in reference 5.

MODERN AND OLD-STYLE INSTRLMENTS TESTED IN THE NASA IRT

LHC (one of each except for the spectrometers):

LEIGH; $J$ and W; ROSEMOUNT; ROTATING MULTI-CYLINDERS; BLADE; LASER SPECTROMETERS ( 5 ASSP, 2 FSSP)

DVM AND DROP SIZE DISTRIBUTION:

LASER SPECTROMETERS (5 ASSP, 2 FSSP, 3 OAP) 


\section{LWC Instruments}

The Leigh and Rosemount are automatic ice accretion instruments that sense the ice as it builds up on the sensing surface. When a critical amount of ice is exceeded, the sensing surface is electrically heated to remove the ice; then the build up-deice cycle is repeated over and over again. Each instrument accomplishes the sensing somewhat differently. The LWC is related to the cycle time and the airspeed.

The Leigh sensing surface is a small tube that is nounted across the inside of a small inlet tube. The inlet is aspirated for heiicopter applications in order to assure that there is a significant air flow over the sensing surface even when the helicopter is hovering. When the ice buildup on the sensing tube exceeds a pre-set thickness, an infra-red light beam (aimed across the sensor tube at a photo detector) is blocked and the deicer cycle is started. The heated compressed air used to aspirate the air flow through the inlet also keeps it free of ice.

The Rosemount LWC sensor tested here is a semi-automatic model that was modified by the user for flight testing of fixed wing aircraft in natural icing. The electronics detect changes in the resonant frequency of the sinall vibrating sensor tube as ice builds up on the surface. Today's versions $o^{\prime}$ this sensor accrete ice up to a point and then they autamatically deice.

The Johnson and Williams ( $J$ and $W$ ) is another automatic LWC instrument, but it does not require the accretion of ice. In fact, it is electrically heated to keep it free of ice. The $J$ and $W$ is basically a hot wire probe that uses the correlation between $L H C$ and the greatly increased heat tranisfer that occurs when droplets strike the hot sensing surface. The wire is stretched across the inside of an inlet tube that is kept free of ice by electrical heat.

The Blade is manually operated and deiced and its data is reduced by hand. The thin blade is attached to a manual actuator and mounted inside a shield. The unit is suspended from the ceiling of the IRT. The blade is made of aluminum bar stock $(0.3 \mathrm{~cm}$ thick $\times 1.9 \mathrm{~cm}$ wide and $25 \mathrm{~cm}$ long). The blade is run out from its shieid for 30 seconds (nominally) to expose the thin $(0.3 \mathrm{~cm}$ ) edge to the icing cloud in the center of the IRT. The thickness of the ice accretion on that surface is then measured with a micrometer and the LWC is calculated by accounting for the collection efficiency. The blade design and procedure used here conformed to that tested at NRC (ref. 6).

The Rotating Multi-Cylinder is also a manually operated instrument. Five cylinders with varied diameters ranging from $0.32 \mathrm{~cm}$ to $11.0 \mathrm{~cm}$, are stacked (one on top of the other with transition pieces) to make the cylinder array. This instrument gives data for LWC. It also gives data for OVM and the drop size disiribution; however, the drop size will not be reported here. In these tests, the rotating cylinder array was run out from a shield (for an appropriate time) into the cloud in the center of the IRT. The LWC is determined from the weight of the ice on each of the cylinders according to the procedure in reference 7 .

\section{Droplet Sizing Instruments}

The laser spectrometer instruments tested were all made by Particle Measurement Systems, Inc. These tests involved five ASSP's (Axial Scattering Spectrometer Probes). two FSSP's (Forward Scattering Spectrometer Probes) and three OAP's (Optical Array Probes). These instruments give data for the LWC, DVM and drop size distribution of a cloud. 
The ASSP and the FSSP covered a drop size range of 3 to $45 \mu \mathrm{m}$ ir. 15 equally spaced size channels. The external shapes of these instruments are different (fig. l(b)). The older ASSP is basically a rod with an inlet tube aligned with the flow. The laser beam passes across the cloud that is flowing through the inlet tube. The FSSP has two tubes sticking out the front end of a trmblike body; the laser beam passes from one tube to the other. Both instruments measure the intensity of the light scattered by the droplets. The scattered light intensity is theoretically related to the droplet size. The number of iroplets counted in each size channel is then periodically sampled and the DVM, LHC and drop size distribution are automatically calculated.

The 0ptical Array Probe (OAP) is geometrically the same as the FSSP's tested. It covers a drop size range of 20 to $300 \mathrm{\mu m}$ in 15 equally spaced channels. The magnified shadow of each droplet is projected onto a linear array of photo diodes. The number of diodes shadowed is related to the droplet size.

Details on how these instruments work and a discussion of possible error sources can be found in reference 5 .

\section{APPARATUS AND PROCEDURE}

A schematic of the NASA Icing Research Tunnel (IRT) test section is sketched on figure $1(a)$. The IRT has accurate instrumentation for recording the tunnel airspeed, the total air temperature and the relative humidity (i.e., frost point temperature). The volume median droplet size (DVM) and liquid water content (LWC) of the spray cloud is set according to the old IRT calibration, which is a function of the air and water pressure to the spray nozzles and the airspeed. The symbols used are defined in appendix $A$. For details about the spray cloud calibration and a discussion of possible error sources, turn to appendix 8 .

The icing cloud instrument comparisons were made with the instruments placed side by side (within the uniform part of the icing cloud shown on figure $1(b)$, or at the same location in the test section for the same (repeated) cloud conditions at another time. The comparisons took advantage of the fact that most ground icing simulation facilities have the following capabilities which are essential for this comparison test. The icing cloud parameters (LWC, drop size (DVM) and drop size distribution) are repeatable. And these parameters are adequately uniform across the cloud. In addition, the icing environment in the tunnel should adequately simulate a natural icing encounter. These points are discussed more fully in appendix $\mathrm{E}$ and in the Results and Discussions Section.

The instrument tests reported herein were done at four separate entry times in the IRT over the course of two years. The instrument installations were somewhat different for each entry. The 1981 entry, where most of the modern instruments were tested, will be described in some detail; the other entries will be descrioed as a variation from that installation.

A special test stand for mounting the modern instruments to be tested in 1981 was installed in the test section of the IRT, as noted in figure l(a) and $1(b)$. The sketch shows two LWC instruments mounted on the airfoil support (i.e.. a $J$ and $W$ probe and a Leigh ice detector). Two laser spectrometers are mounted on the stand. The two spectrometers shown are an Axial Scattering Spectrometer Probe (ASSP) and a Forward Scattering Spectrometer Probe (FSSP). The OAP's (Optical Array Probe) were interchanged with the FSSP because they use the same mounting pad. 
This installation was also used for a limited modern instrument test in 1979; but then only one ASSP and one OAP were tested. Another early test involved only the thin blade, which was mounted in its shield from the celling of the empty tunnel.

Some months after the modern instrument test in 1981, another series of instruments were tested in the IRT. These were the rotating cyl inders, the Rosemount and the same Leigh as was used in the modern instrument test.

To avoid practical difficulties and to insure that the instrument was working properly during the tests, all instruments were installed and checked out by either the manufacturer, or the user (owner) or $h$ is representative. The data taking, data analysis, and report writing responsibilities were performed in such a way that no instrument would be favored.

\section{RESULTS AND DISCUSSION}

The results tor the liquid water content (LWC) instruments are discussed first, then the drop sizing (DVM and distribution) results are discussed. These discussions will include comparisons with the old calibration of the NASA Icing Research Tunnel, which was the main facility used in the development of the icing technology used today. Data showing the effects of temperature, airspeed, drop size and LWC are included. The consequences of the observed errors in these instruments are discussed. Instrument fallures are discussed briefly. And finally, recommendations will be made.

\section{LWC Instruments}

A number of modern and old-style LWC instruments were tested; Table I lists the instruments tested. These instruments were compared at essentially the same location at different times. This procedure takes advantage of the high repeatability of the IRT spray, which is discussed next.

LWC Repeatability. - The percent variation for the best two performing instruments was \pm 12 and \pm 15 percent over many different repeats of the same cloud conditions. The percent variation is one standard deviation of the readings about the average LWC reading. The variation of the LWC at any location in the IRT spray due to errors in setting the air and water pressures to the spray nozzles is typically \pm 5 percent and never more than \pm 10 percent (appen$\operatorname{dix} A$ for details). In other words, the repeatability (i.e., scatter or variation) of the IRT spray is adequately better than the repeatability of the instruments. By the "same cloud conditions" we mean the air and water pressures to the nozzles were the same and the airspeed was the same. Furthermore, the air temperature was cold enough to avoid thermal errors (i.e., water run-off) with the ice accretion instruments. Having established that the IRT spray is more repeatable than the instruments, we move on to the comparisons.

Comparisons between LWC instrumer.t readings and the IRT Calibration. - As discussed in appendix $B$, the LWC in the center uniform region of the IRT test section should be well known in an absolute sense because the liquid flow through the nozzles can be traced back to a liquid flow calibration of the nozzles. This is equally true for any ground icing facility. Therefore, it seems reasonable to use the LWC from the old IRT calibration as a standard for this comparison of LWC instruments. As will be shown later in figure 3 , instruments calibrated independently in other ground icing tunnels verify the 
IRT calibration. Figure 2 contains a comparison of the indicated LWI readings for a number of instruments with the LWC set in the IRT. All of these data were taken over a range of airspeed, LWC and drop size. The air temperature was kept very cold so that there would be no noticeable thermal errors with any of the instruments. The only correction made to the data was a generally small measured correction for the local airspeed, which was higher than the tunnel airspeed because of the support stand blockage (described in appendix B). This comparison shows that all of the instruments, except for the laser spectrometers, are generally in good agreement with the IRT LWC calibration. But let us look at this deviation from the IRT values of LWC statistically.

The percent deviation of each instrument reading from the IRT calibration value is given by

$$
x=\frac{L W C_{\text {indicated }}-L W C_{\text {IRT }}}{L W C_{\text {IRT }}} \times 100
$$

These values of $X$ were statistically analyzed for each instrument. The average value of $X$ is listed in figure 3 for each instrument; this average is the average error of the indicated values relative to the IRT calibration. The statistical scatter of $X( \pm 1$ standard deviation) is also listed in figure 3. This scatter is due mainly to two causes: (a) the repeatability of the instrument and the IRT and (b) the inability of the instrument to properly account for the effect of DVM, LWC and airspeed over a large range of these test conditions.

From figure 3, the $B 1$ ade and the Leigh instrument have an average error which is nearly zero. These same identical instruments were recently tested in the Canadian NRC icing tunnel and in the Addington icing tunnel in England (ref . 8). These tests also found a nearly zero average error compared to their tunnel calibrations. The LWC calibrations of these three icing tunnels are based on the water flow to the spray nozzles and should, therefore, be correct. The fact that the instruments agree with the independently derived calibrations reinforces our belief that the IRT calibration for LWC is correct. Additionally, Hunt (ref. 9) has also verified the calibration of the liquid flow of the IRT spray nozzle.

The instruments above the dashed line on figure 3 measure only LWC. Of these instruments, three (the Leigh, $J$ and $W$ and the $B l a d e$ ) have an average error of nearly zero; the other three are not as close. Only one sample of each instrument was tested here; more than one sample should have been tested to properly evaluate the average error of any given instrument model. All of these instruments essentially have the same scatter about the average (i.e., \pm one standard deviation) of about \pm 20 percent. A large number of $J$ and $W$ sensors were compared in reference 2. This comparison showed that different samples of the same model $J$ and $W$ instrument did not agree with one another or with the NRC icing tunnel calibration any better than the comparisons herein. Notice that the laser spectrometer instruments tested (the ASSP's and FSSP's) are too inaccurate to be used as LWC instruments.

The less than perfect agreement with some LWC only instruments clearly points out the need for more testing of these instruments in ground icing factlities. Reference 2 made a similar recommendation. 
It must be pointed out that the LWC values run in these tests are on the high side compared to the most probable LWC in natural icing (about $0.2 \mathrm{~g} / \mathrm{m}^{3}$ ). Therefore, the IRT tests can be viewed as simulating severe icing conditions. Another difference between the IRT and flight testing is that the LWC in the IRT cloud is steady, whereas the LWC will generally fluctuate an order of magnitude with time as an aircraft flys through a natural cloud.

Effect of temperature. - The previous comparisons were made at a cold enough temperature that thermal errors (caused by water run-off) should not occur with any of the ice accretion instruments. Above a certain temperature the LWC readings will be reduced because some of the impinging droplets will run off the sensing element instead of freezing there.

Figure 4 contains two experimental comparisons which show the effect of total air temperature, airspeed and drop size on the LWC readings of several LWC instruments at the same incident droplet mass flux (LWC $V \mathrm{~V}=$ constant). In each drop size case, the tunnel cloud (LWC, drop size) and velocity were unchanged as the total temperature was increased. lou will notice that for each drop size case, each of these ice accretion instruments had about the same thermal error. For the lower LWC and DVM of most natural icing encounters, the thermal-error temperature would be closer to the freezing temperature.

Consequences of percent error in LWC instruments. - It was previously shown that all of the LWC-only instruments had a scatter ( \pm one standard deviation) in their readings of about \pm 20 percent from the average; the laser spectrometers were far worse. What is the consequence of such a variation or uncertainty ${ }_{\mu}$ One serious consequence of an uncertainty in LWC would be in the resulting uncertainty of the predicted drag coefficient for an airfoil that has accreted ice. Figure 5 contains a comparison where the LWC in the IRT was varied \pm 25 percent about a worst case condition. Figure 5 shows that a \pm 25 percent uncertainty in LWC would cause about a \pm 25 percent uncertainty ir. $\$$. drag coefficient, $C_{D}$, for an airfoil with ice. That uncertainty is probably acceptable; but remember that the LWC variation here corresponds to only a $t$ one standard deviation in the instrument scatter. The consequence of this uncertainty in tests of a deicer system should be even less important.

\section{Drop Size Instruments (Laser Spectrometers)}

A number of modern laser spectrometer instruments were compared in the icing cloud of the IRT. These lasers were several units of the Axial Scattering Spectrometer Probe (ASSP 1, 2, 3, 4, and 5), two Forward Scattering Spectrometer Probes (FSSP 1 and 2) and three Optical Array Probes (OAP 1, 2, and 3). Two of these same instruments were also tested two years before (referred to as ASSP $1^{\prime}$ and FSSP 1'). These instruments were generally compared at different times, taking advantage of the excellent repeatability of the IRT spray. This section will first discuss the data concerned with the volume median drop size, then the drop size distribution will be discussed. The following will be covered: IRT and instrument repeatability, accuracy relative to the IRT calibration and the other instruments, the effect of airspeed, temperature, drop size and LWC. The consequence of the observed error will be covered. And finally, the instrument errors and practicality will be discussed. 
Volume Meaian Drop Size (DVM) Results

Repeatability. - The repeatability of the drop sizing instruments and the repeatability of the IRT spray cloud must be determined together; if they both repeat then there is no problem with repeatability in this experiment. The table below shows the percent variation ( \pm one standard deviation) from many samples of the DVM indications from the various laser spectrometers in the same cloud (i.e., same IRT spray settings and airspeed).

\section{PERCENT VARIATION* IN DROP SIZE (OVM) IN THE IRT}

(Same Airspeed and Spray Nozzle Pressure)

$\begin{array}{clc}\begin{array}{c}\text { Laser } \\ \text { Spectrometer }\end{array} & \begin{array}{c}\text { Samples during } \\ \text { a given spray }\end{array} & \begin{array}{c}\text { Samples from } \\ \text { sprays during } \\ \text { the test period }\end{array} \\ \text { FSSP } 1 & \pm 3 \text { percent } & \pm 4 \text { percent } \\ \text { ASSP } 1 & \pm 2 \text { percent } & \pm 3 \text { percent } \\ \text { ASSP 2 } & \pm 3 \text { percent } & \pm 3 \text { percent } \\ \text { ASSP } 3 & \pm 2 \text { percent } & \pm 7 \text { percent } \\ \text { ASSP 4 } & \pm 3 \text { percent } & \pm 7 \text { percent }\end{array}$

* $t$ one standard deviation of the OVM indications as a percent of the mean value for that probe

The first column of the table shows that the percent variation during a given spray is about \pm 3 percent (corresponds to less than $\pm 1 \mathrm{um}$ ). The next column is the percent variation during different sprays but at the same spray settings; again the variation with a given instrument is less than \pm 1 um. appendix $B$ describes data taken during a few traverses across the spray (across the spray from many nozzles). The variation here was also less than $\pm 1 \mathrm{um}$. Based on an error analys is (appendix B), pressure setting errors will affect the drop size even less. Clearly, the IRT spray is both repeatable and uniform, such that DVM data from different instruments can be compared with good accuracy.

Comparisons between instruments. - We previously showed that the laser spectrometers were poor instruments for LWC. It would be instructive to compare the indications of LWC and DVM from a number of instruments that were all immeried in exactly the same cloud (i.e., same IRT spray settings and airspeed). These comparison data are plotted in figure 6 , where the instruments were all immersed in a cloud of $16 \mathrm{\mu m}$ and $1.02 \mathrm{~g} / \mathrm{m}^{3}$ and an airspeed of 320 $k$ llometers ner hour. The estimated repeatability of the IRT spray causes a small scatter as shown on figure 6 . Here we see quite graphically that the OVM and LWC data from a given instrument in the same cloud scatter a small amount; but the indications from different instruments differ widely. Herein lies the problem with these instruments. Even after careful standard calibrations (described in ref. 5), there is a significant variation between instruments in their indication of OVM, and a very large variation in their indication of LWC.

Comparison to the old IRT calibration. - The old drop size calibration of trie spray nozzles in the Icing Research Tunnel (IRT) was performed in the early 
1950 's by a combination of methods that were checked against one another. The old calibration was not an absolute calibration. The old calibration was a relative calibration because it assumed that the theory for droplet impingement (i.e., capture efficiency) was correct. With that assumption, the drop size (DVM) was determined from capture efficiency data on blotter covered Jouwkowsk $f$ airfoils and rotating cylinders by the dye transfer technique (ref. 10). These results compared favorably with rotating cylinder (ice accretion) measurements made much later by others (ref. 11).

Since the IRT was the facility in which most of the icing technology was developed, it is important to compare the DVM measurements of the laser spectrometers with the old IRT spray calibration. This comparison is also important because the laser spectrometer measurement is independent of the old drop size calibration, which was relative. If the spectrometer drop size indications agree with the old IRT calibrations, then the new and old methods would be in agreement; if they do no: then there may be a problem.

Figure 7 contains a comparison of the DVM indications from several laser spectrometers and the OVM from the IRT calibration, for a large range of LWC and airspeed conditions. The laser data have a large scatter, primarily due to the variations between instruments. The data scatter ( \pm 1 standard deviation) of all the ASSP data is \pm 20 percent, which corresponds to a scatter of $\pm 4 \mathrm{~mm}$ at $20 \mathrm{\mu m}$. This scatter is larger than the scatter for the ASSP data shown on figure 6 which is about $\pm 2 \mu \mathrm{m}$ at $20 \mathrm{\mu m}$. The small sample of data on figure 6 are only for one repeated spray condition and airspeed, whereas the data on figure 7 cover a large range of DVM, LWC and airspeet. The variation of the sensitivity of the instruments to changes in LWC, DVM and airspeed is the likely explanation for the larger scatter on figure 7.

The data from the one working FSSP is about 20 percent higher than the data from the various ASSP's. The average line through the ASSP data is about 20 percent higher than the old IRT calibration. If you put the ASSP and FSSP data together, the scatter ( \pm one std. dev.) at $20 \mathrm{\mu m}$ is almost $\pm 6 \mathrm{um}$.

Hunt (ref.9) has made detailed spectrometer measurements of the drop sizes from the IRT spray nozzle in his small icing facility with his unique nonotirusive laser spectrometer. His spectrometer measurements are in very close agreement with the old IRT calibration curves for DVM at $V=240 \mathrm{kilometers}$ per hour. He also verified the old DVM calibrations of spray nozzles useo in many other ground icing tunnels. This comparison is possible because the tu.tnel effects on the droplets (e.g., evaporation, freeze out, etc.), as they travel from nozzle to test section, are generally negligible (appendix 8 ). Hunt's spray nozzle measurements with the same spectrometer have put the calibrations of many ground refrigerated icing facilities on a good comparable basis. It may be a good idea to define his spray nozzle measurements of the DVM for these facilities as an interim calibration standard and use the refrigerated facilities as reference facilities. This will be discussed more under Recommendations.

Effect of velocity. - Figure 8 shows the effect of tunnel airspeed on the laser spectrometer readings for the same spray settings. The indicated drop size is constant, not a function of the test section airspeed. This is clearly not in agreement with the old IRT calibration, which is alsn shown in the figure. Hunt (ref. 9) observed the same airspeed independence when he tested the IRT spray nozzle in his icing facility. This constancy should not be surprising because in both facilities the droplets are formed near the spray nozzles where the droplet velocities are very high compared with the low air velocity in the large tunnel plenum. 
The old IRT drop size calibration should be changed so that the velocity dependence is removed; indeed equation A-2 for DVM should be evaluated at $V=240 \mathrm{kilometers}$ per hour $(150 \mathrm{mph})$ regardless of the actual airspeed in the test section. Unfortunately, when all the data on figure 7 was corrected to $240 \mathrm{kilometers}$ per hour the scatter was essentially the same, because most of the scatter was caused by differences between the instruments.

The fact that the drop size is independent of the tunnel airspeed, in disagreement with the old IRT calibration, would seem to raise a question about the adequacy of the old dye transfer data or how it was used in the old IRT calibration (ref. 10). However, the ciye transfer data was taken at only one airspeed; therefore, the old airspeed calioration can be changed without consequence.

Consequences of DVM errors. - From the previous discussion there is as much as a $\pm 6 \mu \mathrm{m}$ scatter at $20 \mu \mathrm{m}$ in measuring DVM between various ASSP and FSSP spectrometers. What is the consequence of this worst case uncertainty $\mu_{\mu}$ Let us determine the consequence by directly measuring the change in derodynamic degradation of an airfoil caused by a change of $\pm 6 \mu \mathrm{m}$ in the drop size setting of the icing cloud in the IRT. Figure 9 shows that this small change in drop size ( \pm 30 percent from ref. case) has a surprisingly large effect on the ice shape that forms, which in turn causes a much larger change in the resulting drag coefficient. This experiment was repeated with the same result. The reference case on figure 9 (LWC $=1.3$, DVM $=20 \mathrm{\mu m}$ ) is the same as the reference case on figure 5. Additional experiments were also performed (not shown here) at higher and lower temperatures (i.e., equivalent to freezing fractions nearer 0 and 1 , respectively), and also for less accretion time; all of these cases exhibited a much lower variation in the drag coefficient than shown on figure 9. The "worst case" example on figure 9 strongly suggests that an absolute standard (or at least a relative standard) is required so that all laser spectrometers can be referenced to one another; standard calibrations are not enough. This strong effect of drop size indicates that all icing simulation facilities must generate drop sizes that are close to the most likely drop sizes in nature (OVM $=15$ to $20 \mu \mathrm{m}$ according to ref. 12). The above concerns only apply to tests where the aerodynamic consequence of icing is desired. The effect of the $\pm 6 \mu \mathrm{m}$ uncertainty will probably not be very important for a deicing test.

\section{Normalized Drop Size Results}

An icing cloud can be described by the LWC, DVM and the drop size distribution. While instrumentation accuracy must be high for LWC and DVM, errors in the drop size distribution should not have a large effect on the ice accretion and resulting aero degradation (ref. 13). It is convenient to normalize the drop size distribution by the LWC and DVM, because the normalized distribution may not change very much as the LWC, DVM and other parameters change.

The first question is how repeatable are the normalized orop size distributiuns for the same IRT spray settings. Figure 10 contains a comparison of the normalized drop size distributions indicated by several laser spectrometers with the same IRT spray conditions (OVM $=16 \mu \mathrm{m}, L W C=1.02 \mathrm{~g} / \mathrm{m}^{3}, \mathrm{~V}=320$ $\mathrm{km} / \mathrm{hr}$ ). We see the same results we Saw for OVM and LWC with these instruments. A given instrument generally repeats the same indicated normalized distribution for the same cloud; therefore, the IRT cloud distribution repeats quite closely. But the agreement tetween instruments is again poor. The LWC and DVM between instruments does not repeat well, but it was hoped that the normal- 
ization by the indicated values of LWC and DVM would still permit the normalized distribution to be the same for each instrument. Unfortunately, as the figure shows, it did not work out that way.

A quantitative way to look at the repeatability of the shape of the normalized distributions is to fit the distributions with an equation and look at the variation of the parameters of the equation that give the best overall fit of the distribution data. The Langmuir distribution is the most convenient way to do this because only one parameter, $n$, is adjusted to give the overall best fit (ref. 14). The Langmuir distribution fits the distribution data almost as well as the Gamma distribution which uses three parameters (ref. 5).

The results for $n$ are listed in figure 11, for the same repeated spray conditions and airspeed used in figure 10. The small scatter ( \pm one standard deviation) in best-fit values of $n$ indicate again that the normalized distributions for a given instrument and also for the IRT spray are highly repeatable. The differences in the best $f$ it values of $n$ for each instrument again tell us that the instruments do not agree with one another.

Part $b$ of figure 11 presents results for the same spray conditions but at different airspeeds. The normalized distribution did not change with airspeed, as noted by the small scatter ( \pm one standard deviation) in the values of the exponent $n$ for each instrument. Again, the variation in $n$ was large between instruments.

The next question is how close is the normalized distribution of the IRT cloud to the normalized distribution in natural clouds. The distribution from ten different natural icing cloud encounters with different laser spectrometers were analyzed in reference 5 . They found that these distributions were best fit by $n=1.05 \pm 0.15$. That would correspond to a $B$ Langmuir distribution. The value of $n$ is 1 for a $B$ distribution, 1.5 for a $C, 2$ for $D$ and 2.5 for $E$. According to figure 11, the IRT spray (depending upon which instrument you believe) varied from $n=1.25$ to 1.95 ; that corresponds to between $B$ and $D$ Langmulr distribution. Reference 1 stated that the distribution (based on old-style instruments such as rotating cylinders and oil slides) varied from $B$ and $C$ for natural clouds and between $B$ and $E$ for the IRT clouds. By either comparison, the IRT cloud has a somewhat broader distribution than generally exists in nature. But as said before, this difference should have very little effect upon the ice accretion and the resulting aero degradation caused by the tce.

\section{CONCLUDING REMARKS}

A large number of modern and old-style icing cloud instruments were tested ano compared in the repeatable spray cloud of the NASA Icing Research Tunnel (IRT). The following conclusions resulted for the LWC and drop sizing instruments.

\section{LWC Instruments}

1. The average of the LWC readings for the Leigh and the Blade agreed almost exactiy with the IRT calibration (based on nozzle water flow). These same instruments were also found to be in agreement with the independen calibrations of the Canadian (NRC) icing tunnel and a British icing tunnel. Therefore, it is reasonable to consider the calibrations of all three facilities to be absolute and correct.

2. The laser spectrometers that were tested proved to be too inaccurate to be used for LWC measurements. 
3. The indications of the LWC-only instruments had a scatter about the average of \pm 20 percent ( $x$ one standard deviation) over a large range of tunnel settings. The IRT scatter caused by setting errors was generally about \pm 5 percent.

4. All ice accretion instruments have about the same error due to liquid running off before it freezes.

5. The \pm 20 percent uncertainty in the LWC readings should not cause problems in aero-penalty measurements or in deicer experiments.

6. The fallure rate of some of the automatic LWC instruments is a problem (ref. 5 for detalls).

\section{Drop Size (OVM) Instruments}

1. A given working instrument in the same (repeated) spray condition, proved to be highly repeatable in its indications for DVM and normalized drop size distribution; this also implies that the OVM of the IRT spray is also highly repeatable.

2. There were very large variations in the readings of individual instruments of the same design. The scatter ( \pm one standard deviation) for the six spectrometers tested over a large range of cloud conditions was \pm 30 percent (or $\pm \overline{\mu m}$ for a $20 \mu \mathrm{m}$ cloud).

3. Tnis large uncertainty in the DVM can cause an unacceptat le variation in aero-penalty measurements; but the effect in deicer experiments would probably be small.

4. The average of the ASSP readings was 20 percent higher than the old IRT calibration for DVM; the FSSP was 40 percent higher. But Hunt's laser measurements agreed very closeiy with the old IRT calibration ano with the calibrations of other icing tunnels.

5. Normalized drop size distribution data in the same cloud repeated well for the same instrument; but the distributions from different instruments did not agree.

6. The fallure rate of the laser spectrometers was too high, and quite erroneous results occurred--even with experienced operators, caretul standard calibrations, and tests that were run in a well known and repeatable cloud (ref. 5 for detaila).

\section{RECOMMENDATIONS}

1. The results of this instrument comparison test program clearly showed that calibration standards are critically needed. Therefore, the following specific recommendations are made:

(a) The highly repeatable spray cloud (year after year) of refrigerated icing tunnels should be used as a reference standard for LWC and OVM. Hunt (ref. 9) has put the nozzle spray clouds of these facilities on a common basis by measuring the DVM from the ir spray nozzles using the same spectrometer. It is recommended that his measurements be used as the basis for an interim calibration standard of these reference facilities. Furthermore, the LWC calibration of all refrigerated icing facilities should be put on the same basis by using the same LWC instrument in all facilities. 
(b) In flight tests, portable spray rigs should be used to chcck out the laser spectroneters. This recomendation assumes that the spray will

prove to be repeatable and insensitive to changes in the environaent.

2. The high failure rates of some of the automatic instruments suggests that wore development testing in icing tunnels is needed and they should be operated and the data analyzed by experienced personnel.

3. The instrument comparisons made here in were extensive but more instruments need to be cospared in a similar marner. 


\section{APPENDIX A}

\section{SMMOLS}

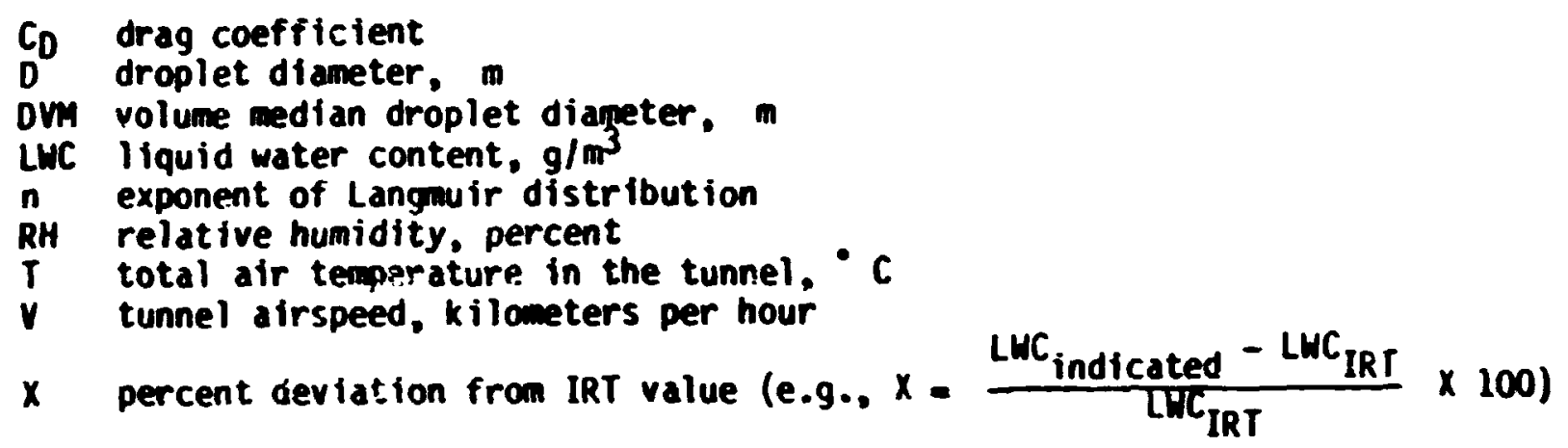




\section{APPEMOIX $B$ \\ DISCUSSION OF THE MASA IRT. ITS CAPABILITIES AND ERROR SOLRCES}

The MASA Lewis Icing Research Tunnel (IRT), its capabilities, old caltoration and possible error sources are discussed in this section.

\section{Description of the IRT and Its Icing Cloud}

The Icing Research Tunne? at the Lewis Research Center of MASA is a closed loop refrigerated wind tunnel that was built in 1944. Its test section is 1.8 meters high and 2.7 meters wide. The airspeed in the test section can be varied from $30 \mathrm{kilometers}$ per hcur to $480 \mathrm{kilometers}$ per hour; and the total temperature can be varied from above $0^{\circ} \mathrm{C}$ down to abocit $-30^{\circ} \mathrm{C}$. According to the old calibration, the icing cloud issuing from 77 air atomizing spray nozzles can produce a drop size (DVM) range of from 10 to 20 and a liquid water content (LWC) of from 0.5 to $3.5 \mathrm{~g} / \mathrm{m}^{3}$.

The cld orop size and LWC calibration equations are functions of the air and water pressure to the spray nozzles and the tunnel airspeed, as shoyn oy equations $(A-1),(A-2)$, and $(A-3)$. The liquid water content in the $\mathrm{g} / \mathrm{m}^{3}$ at the center of the tunne? is given by

$$
\text { LHC }=0.085 \frac{\left(77 \mathrm{Wl}_{\ell}\right)}{V}
$$

and the volume median drop size in microns is given by

$$
\text { DVA }=(43.9-\sqrt{3.48 V})\left[\frac{1.09 \mathrm{Wl}_{2}}{\left(\frac{\text { air }}{1.13}+10.0\right)}\right] \pm 0.0052 v
$$

where the liquid flow from each of the 77 spray nozzles. Wh, is given by

$$
H_{2}=\sqrt{38.7\left(P_{H_{2} \mathrm{O}}-\mathrm{P}_{\mathrm{air}}\right)}
$$

For historical consistency, these old calibration equations are in the old English units (e.g.. $V$ is the tunnel airspeed in $\mathrm{mph}$, the air and water pressures. $P_{\text {air }}$ and $P_{H_{2}}$, are in pounds per square inch gage, and water flow to each nozzle is in bounds per hour.

Please note that the LWC varies inversely with the airspeed and the drop size is a weak function of airspeed. The spray bars are in the large plenum upstream of the test section, where the velocity never exceeds $50 \mathrm{kilameters}$ per hour. Compared to the velocity shears in and near the nozzle, changes in the plenum airspeed should have no effect on the drop size unless the droplets evaporate differently at a different tunnel airspeed; we will consider this shortiy.

The calibration equations for drop size and LWC are not functions of the air temperature. But the temperatures of the pressurized air and water to the nozzle are kept at $85^{\circ} \mathrm{C}$ in order to assure that the droplets do not freeze as 
the pressurized air cools while passing thrcugh the choked nozzle (this is discussed more, shortly).

Not every drop size and LWC can be attained at every airspeed because of linitations of the spray flow systems. For example, the old calibration limits were:

$$
40<P_{\text {air }}<75 \text { psig, } P_{\mathrm{H}_{2} \mathrm{O}}<110 \text { psig, } 10<\left(P_{\mathrm{H}_{2} \mathrm{O}}-P_{\text {air }}\right)<65 \text { psig }
$$

In addition, the old calibration placed limits on the maximum and minimum droplet sizes attainable:

$$
\text { 10. } \leq \text { DVM } \leq 20 \text {. microns }
$$

Recent laser spectrometer measurements with the IRT nozzle (ref. 9) have shown that droplets up to $40 \mathrm{~mm}$ can be obtained. And our experiments have shown that the air pressure and pressure difference limits can be lowered substantially, without compromising the cloud. Mevertheless, the conditions used in this test program were within the old limits, except for a few data points that were taken at lower air pressures and somewhat larger droplets.

The old calibration of the IRT was performed in about 1955 with a combination of methods. For drop size, the Joukowski airfoil and the rotating cylinder were used with the dye transfer experimental technique at one airspeed. Assuming the theory for capture efficiency was correct, the drop size was determined by measuring the local variation of the amount of dye that was absorbed by blotters on these two surfaces (ref. 10). These results compared favorably with oil slide and rotating cylinde: measurements. The old calibration was checked in 1969 (ref. 11) and found to be \pm 5 percent on LHC and drop size. However, the IRT calibration has been questioned recently. Therefore, one of the goals of tlose experiments is to check out the old calibrations with modern instruments; if they both agree with one another, then both the modern instruments and the IRT calibration will have been substantiated.

\section{Discussion of Sources of Error}

There are a number of error sources to discuss which can cause an improper simulation of natural icing. There can be errors in the air conditions, in the test section (e.g., dirspeed, air temperature, and in the relative humidity). The air in between the droplets in the cloud is assumed to be saturated (same as in natural clouds), or it is assumed that the effect of it not being saturated would not be noticeable. There can be errors in setting the cloud spray pressures which cause errors in the LWC and DVM. The droplets shouid be at the same velocity and temperature as the surrounding air in order to properly simulate a natural icing cloud. The airspeed, temperature, and LWC and DVM should be reasonably uniform across the tunnel. The instruments and their supports will cause small changes in the velocity where the instruments are located. The ice buildup on the probes can cause them to operate improperily and with error. In fact, we had to wrap the laser spectrometers with stean tubes in order to permit them to operate for reasonable time durations in the righ LWC environment of the IRT. The effect of the steam tubes must be determined. And lastly, a natural icing encounter generally is characterized by large changes in the LWC as the afrcraft flys along. The old-style instruments generally sampled the cloud for a long period of time compared to the modern instruments. The old instruments gave data that is naturally time averaged 
like any ice accretion. Time averaging differences between modern and old instruments are a potential source of error. The IRT cloud is steady so this potential error is beyond the scope of this paper.

Air conditions. - The IRT airspeed is measured with heated pitot-static probe that is periodically calibrated; it is considered to be accurate to better than \pm 1 percent. The tunnel test section airspeed is uniform except for the boundary layer which is less than $15 \mathrm{~cm}$ thick on the tunnel walls.

The total air temperature is measured by many droplet shielded thermocouples on the turning vanes upstream of the spray bars (fig. 1(a)). The heat exchanger segments of the refrigerator are adjusted before and during an icing run so that the temperature is generally uniform to with in about $\pm 1 / 2^{\circ} \mathrm{C}$ of the center; the center is held even closer than that to the desired temperature. These thermocouples are periodically calibrated to about $\pm 1 / 2^{\circ} \mathrm{C}$. The relative humidity of the dry (droplet free) air upstream of the spray bars is measured by a modern General Eastern frost point instrument, wich is periodically checked at $0^{\circ} C$ with an ice bath. Long term measurements have shown that the relative humidity upstream of the spray bars reaches a steady value of about 70 percent after the first spray. Calculations using the computer code developed by AEDC (ref. 15) and the 70 percent initial condition, indicate that the cest section will have essentially saturated air over the tunnels possible range of velocity, drop size, LWC or air temperature (below $0^{\circ} \mathrm{C}$ ).

Spray conditions. - One of the purposes of this experiment is to deterinine if the IRT calibration for LWC and droplet size agree with the indications of modern instruments. The comparisons with the modern instrument comparisons are in the Results section of this paper. The comparisons discussed here are therefore limited to an error analys is using the old calibration equations, questions reiated to uniformity, and questions related to the thermodynamic changes in the spray as it travels frrm the spray bars into the test section of the IRT.

The old calioration equation for LWC in the center is given in equations $(A-1)$ and $(A-3)$. It shows that the errors in the LWC would be due to errors in setting the air ario water pressures to the spray, because the velocity errors are negligible; ard also because the nozzles are well maintained and checked, and demineralized water is used. The maximum error in setting the water or air pressure is considered to be \pm 2 psig. Based upon an error analysis and the frequencies of the pressure settings used in this test program, the average variation (repeatability) in the LWC would be \pm 5 percent with a standard deviation of \pm 5 percent.

The old calibration equation for drop size (eqs. $(A-2)$ and $(A-3)$ also indicate that errors in drop size would be due to errors in setting the air and water pressures. The maximum error in setting $\mathrm{P}_{\text {air }}$ or $\mathrm{P}_{\mathrm{H}_{2} \mathrm{O}}$ is $2 \mathrm{ps} \mathrm{fg}$, which will generally cause an error in the drop size of less than $\pm 1 \mu \mathrm{m}$. Questions related to the absolute accuracy of the old drop size calibration will be discussed in the Results section.

Spray uniformity. - The question of whether the drop size is uniform across the tunnel is really a question of whether the drop size from each spray nozzle is the same. Several samples of the standard IRT nozzle have been run (ref. 10) and found to repeat well. A short survey across of the cloud will pass through the spray of large number of nozzles and adequately answer the question. Two separate traverses of \pm 1 and \pm 2 feet from the center of the 
test section were performed with a laser spectrometer; the indicated drop size was the same within \pm 1 un.

The uniformity of the LWC across the tunnel is not as good. Uniformity was determined by measuring the ice accretion of an array of 2 inch diameter vertical cylinders that were placed at many positions across the test section. The velocity and drop size are uniform over a much larger region than the LWC, and the LWC uniformity measurements were made at a very cold temperature. Therefore, the ice accretion uniformity is a direct measure of the LWC Uniformity. These measurements indicated that the cloud LWC was uniform (within \pm 20 percent of the LWC in the center) inside of a $0.6 \mathrm{~m}$ high by $0.9 \mathrm{~m}$ wide rectangle in the center of the test section (fig. 1(b)). The instruments were located within a smaller region that was uniform to 10 percent. The uniform region did not noticeably change size over the range of conditions of these experiments. The LWC at any point will be repeatable to: 5 percent. Any variation caused by nonuniformity will surely be less than the variations between the instruments.

Oroplet temperature and velocity. - In natural icing it is usually assumed that the temperature and velocity of the droplets is that of the surrounding air and not frozen. These droplet conditions are extremely difficult to measure. The AEDC computer code (ref. 15) was used to calculate these droplet parameters. For the range of conditions of these experiments, the droplet velocity and temperature differences from the surrounding atr were much less than the inaccuracy in measuring the IRT airspeed and total temperature of the air. Another question: does the spray cloud go around the tunnel and re-enter the test section frozen or with much larger or smaller droplets $\mu$ A walk around the tunnel (down wind) after an evening of icing runs answers those questiors easily. One quickly observes that the cloud accretes out of the air as it passes through turning vanes, screens, etc., until finally very little accretes out as it passes through the small openings in the refrigeration heat exchanger. There is no accretion on the turning vanes just upstream of the spray bars. A microscopic look at the snow-like dust on the floors reveals there are no frozen droplets (i.e., no frozen spheres in the $1050 \mathrm{\mu m}$ range, only jagged pieces of frost that accreted on surfaces and were shed). There would be frozen droplets if the pressurized air and water were not preheated to $85^{\circ}$. C before it passes through the choked spray nozzles.

Effect of instrument support. - The incident local velocity for a given instrument can be affected by the support and traverse holding the array of intruments in the tunnel (fig. $1(a)$ and $1(b)$ ). These common wind tunnel velocity corrections were measured by mounting pitot-static velocity probes at the locations of the instrument measuring locations, without the instrument in place; these measurements were compared to the tunnel's standard pitot-static probe. The maximum local velocity correction was 20 percent; most corrections were less than 5 percent.

Effect of steam tube wrap. - The laser spectrometers required an external wrapping of small steam tubes and insulation in order to increase the heating to the probes internal and external surfaces. Without this additional heating, the probes would give incorrect LWC and DVM readings after short spray time (fig. 12). It was thought possible that this fix might adversely affect the LWC and DVM readings compared to what they would be for the unmodif fed instruments before lcing affected the readings. A number of experiments were performed to check this question. There proved to be no difference in the read- 
ings (Table 4.4 in ref. 5) for either the ASSP or FSSP instruments. Therefore, the steam tube wrap fix greatly extended the run time in the icing cloud of the IRT without itself causing any error.

\section{REFERENCES}

1. Von Glahn, V.H., "The Icing Problem - Current Status of NACA Techniques and Research," AGARD-AG-19/p9, 1955.

2. Strapp, J. W. and Schemenauer, R.S., "Calibrations of Johnson - Willilams Liquid Water Content Meters in a High Speed Icing Tunnel," Journal of Applied Meteorology, Vol. 21, Jan. 1982, pp. 98-108.

3. Hunt, J. O., "Engine Icing Measurement Capabilities at the AEDC, " Icir.g Testing for Aircraft Engines, AGARD CP-236, Aug. 1978.

4. Keller, R., "Measurement and Control of Simulated Environmental Icing Conditions in an Outdoor Free Jet Engine Testing Ground Facility, "Icing Testing for Aircraft Engines, AGARD CP-236, Aug. 1978.

5. Takeuchi, D., Jahnsen, L. Call ander N., and Humbert M., "Comparison of Modern Icing Cloud insiruments," NASA CR-168008, 1983.

6. Stallabrass J. R., "An Appraisal of the Single Rotating Cylinder Method of Liquid Water Content Measurement," National Research Council Report LTR-LT-92, 1978.

7. Brun, R., Lewis, W., Perkins, P., and Serafini, J., "Impingement of Cloud Droplets on a $\mathrm{Cy}$ linder and Procedure for Measuring Liquid-Hater Content and Oroplet sizes in Supercooled Clouds by Rotating Cylinder Method," NACA Report 1215, 1955.

8. Corley-Byrne P.; Leigh Instrument Co., Ottawa, Canada: Personal Communication, 1982.

9. Hunt J.; Sverdrup InC., AEDC, Arnold AFS, TN Personal Communication, 1982.

10. Gelder, T., Smyers, W., and von Glahn, U., "Experimental Oroplet Impingement on Several Two-Dimensional Airfoils With Thickness Ratios of 6 to 16 Percent," NACA TN-3839, 1956.

11. "Measurement of IC ing Cloud Parameters," Lockheed Report, LR-22469, 1969. Appendix B.

12. Bowden, D.T., Gensemer, A. E., and Skeen, C. A., "Engineering Suimmary of Airframe Icing Technical Data," Federai Aviation Agency, FAA-ADS-4, 1964. Dec. 1963.

13. Newton D., "An Integrated Approach to the Problem of Aircraft Icing," AIAA Paper 77-1218, Aug. 1978.

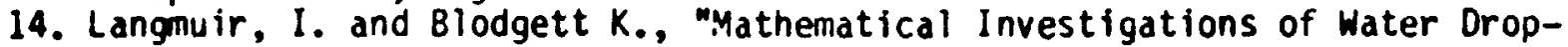
let Trajectories," General Electric Research Lab., Report No. 5418, 1946.

15. Willbanks, C and Schultz, R., "Analytical Study of Icing Simulation for Turbine Engines in Altitude Test Cells," ARO, Inc. Report ARO-ETF-TR73-59, AEOC-TR-73-144, Nov. 1973. 


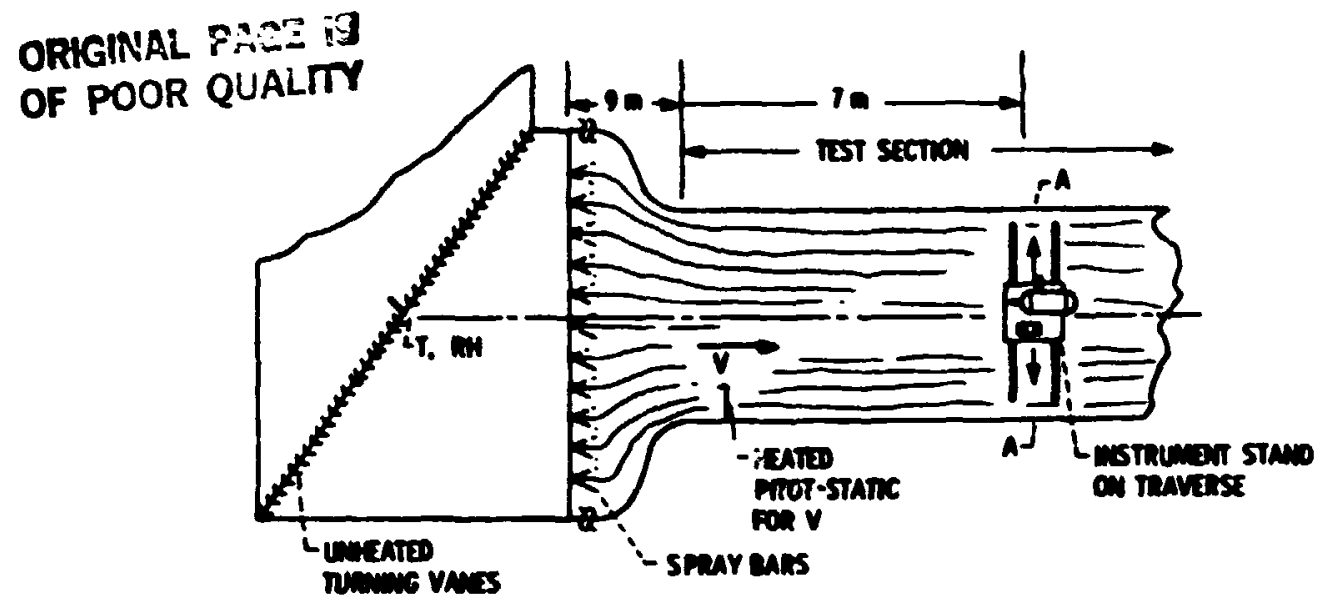

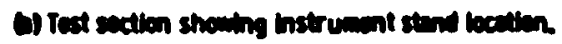

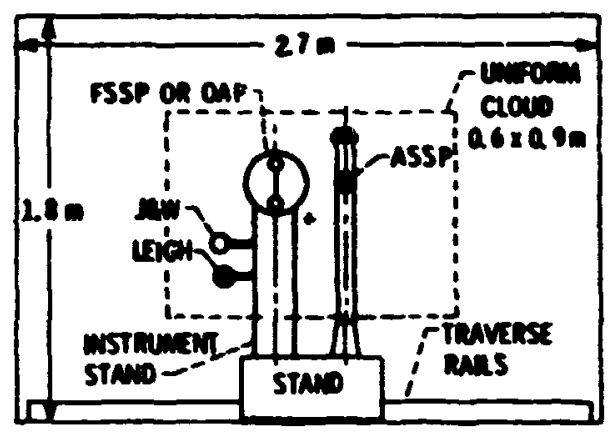

Ol Instruments en thow doding comstrem at A-AL

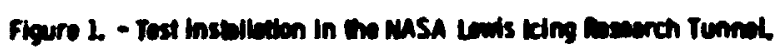

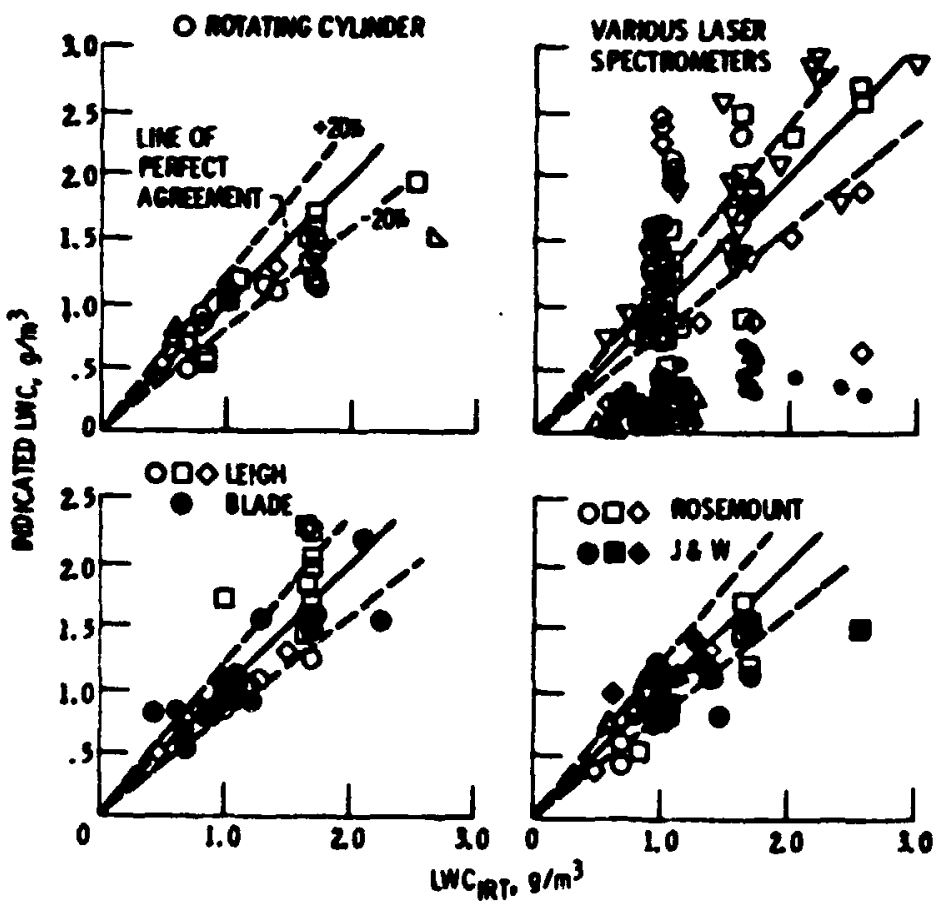

Figure 2 - Comprison of LwG instruments b inf callerction. Tolu ar binardures $<-15^{6} \mathrm{C}$. 
ORIGINAL RA-2:-

OF POOR QUALITY

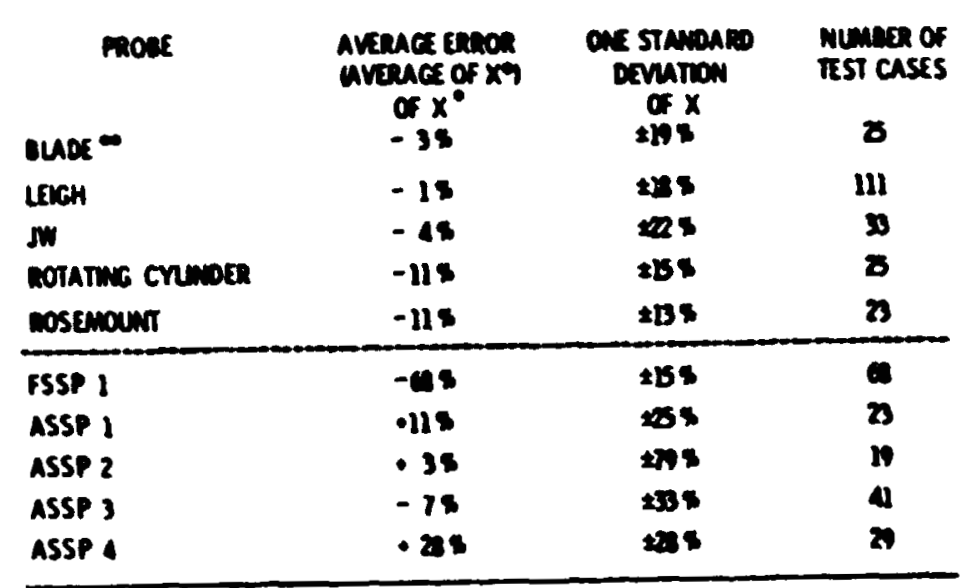

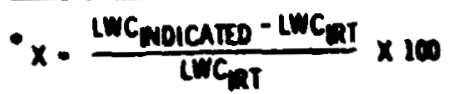

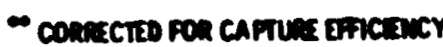

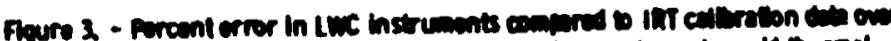

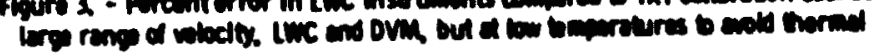
errors.
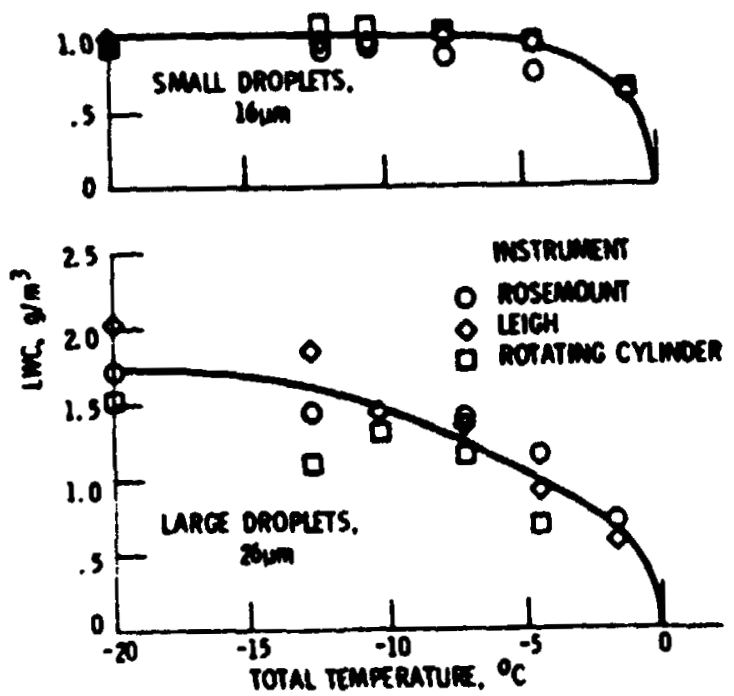

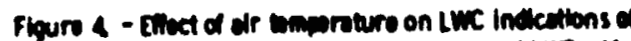
cowral kes cecretion instrumants at conswent LWC $\cdot V$. 
ORIGINAL PROE te

OF POOR QUALTIY
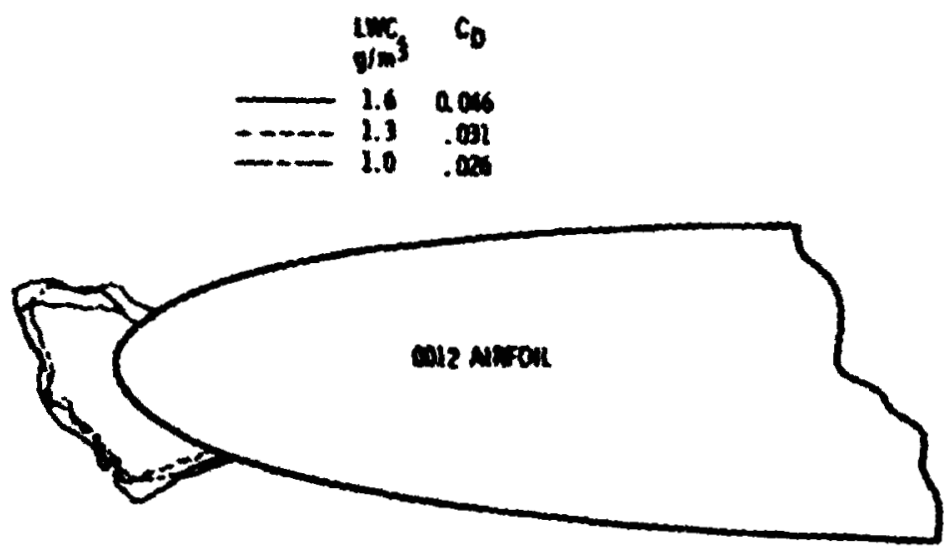

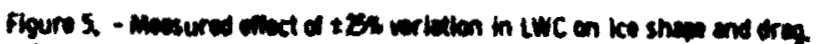

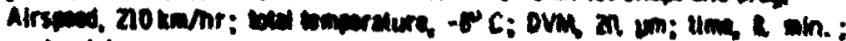

anging ifm

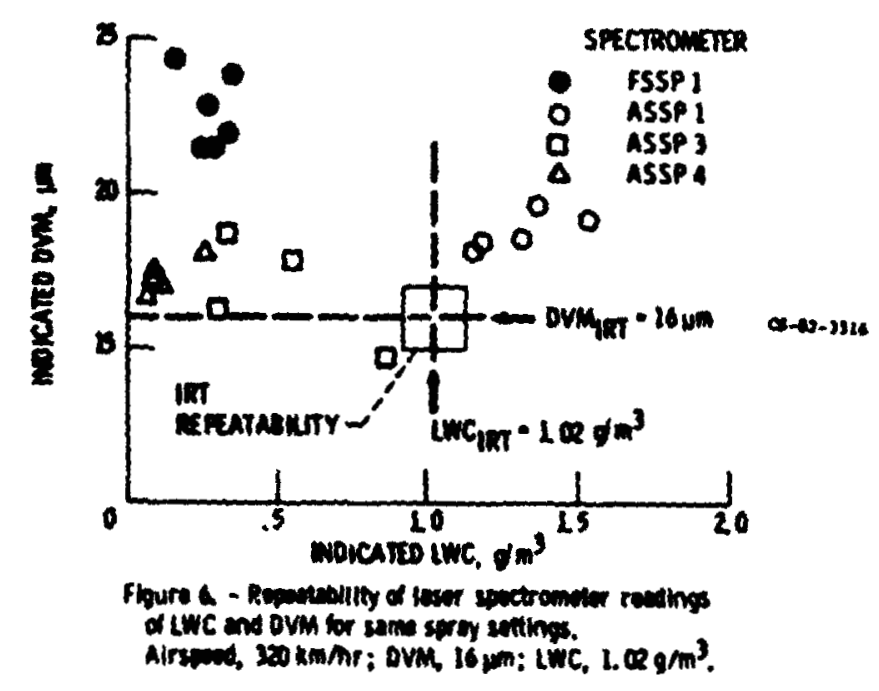




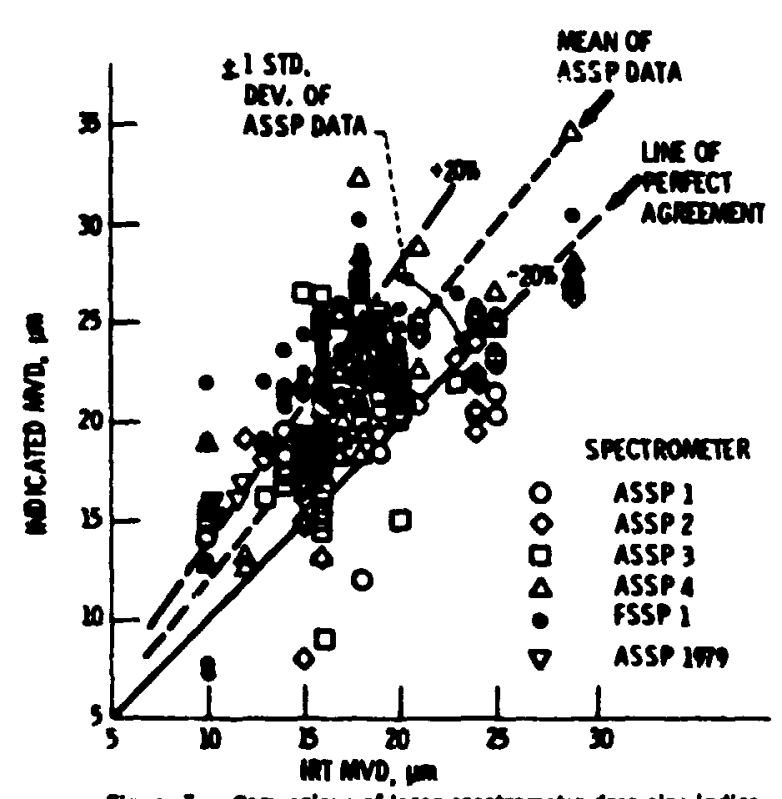

CRI:

OF PCUR Qufatit

Floure 1. - comprison of laser spectrometur trop size Indicer

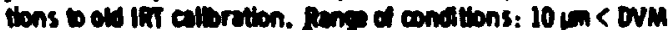

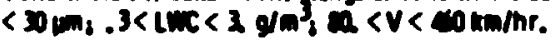

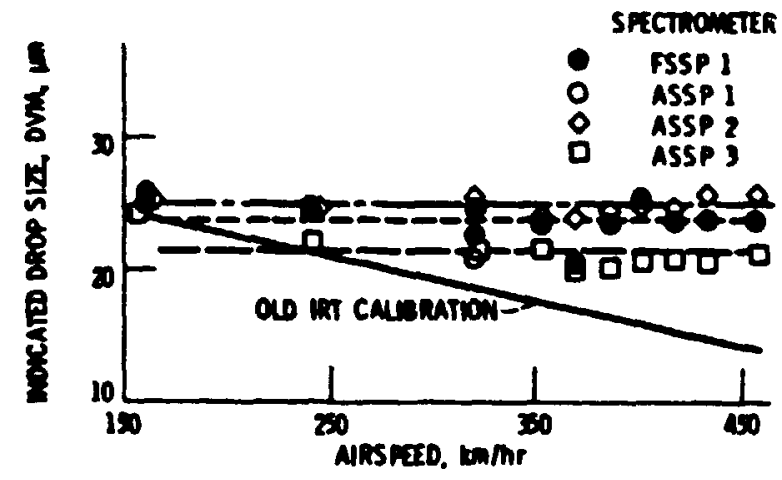

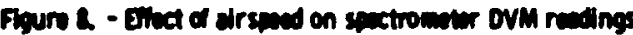

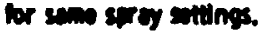
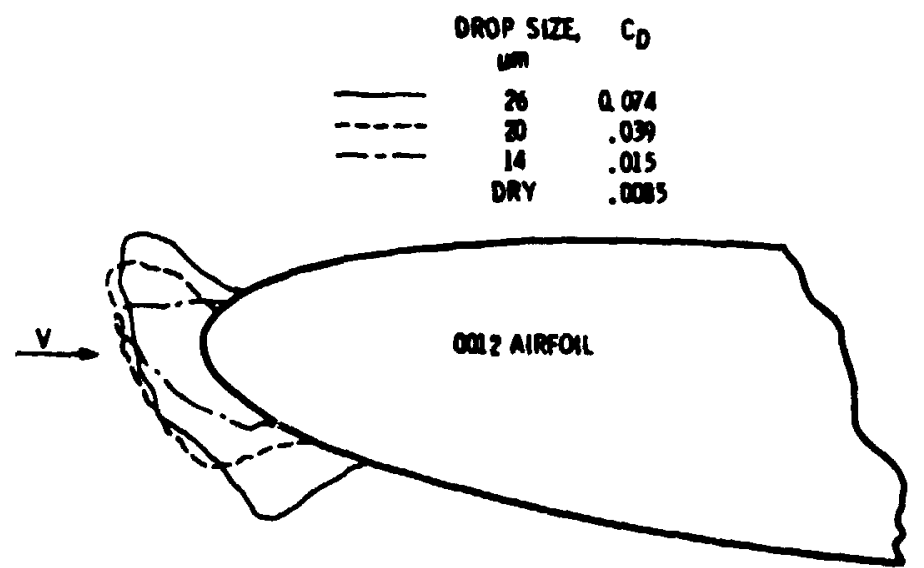

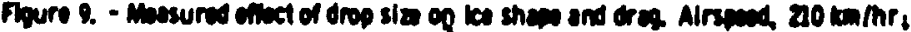

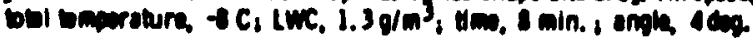


ORIGINAL PAGE

OF POOR QUALTTY

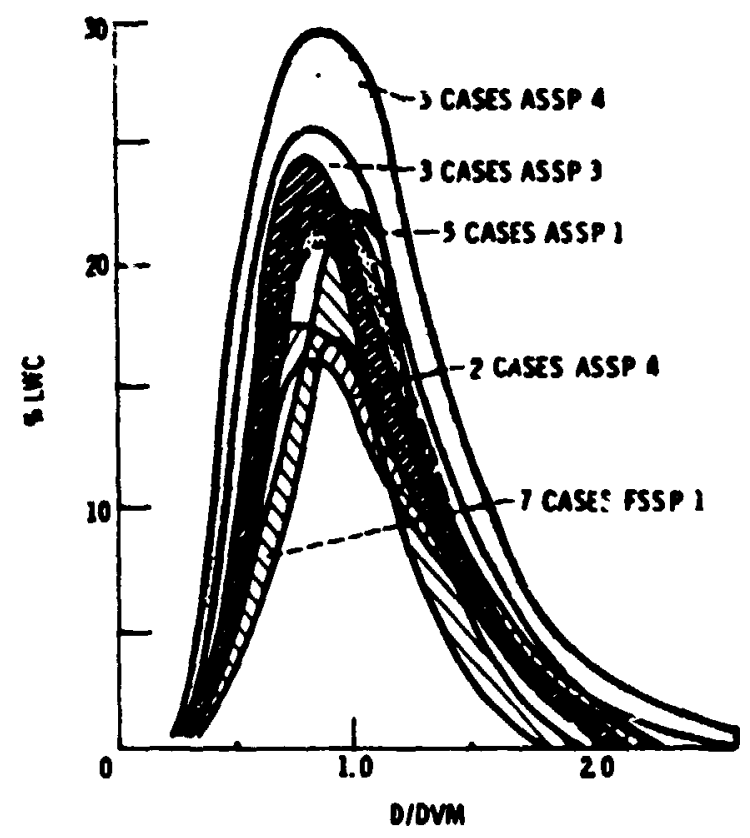

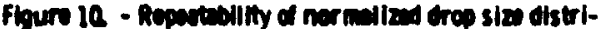
buten for some sproy exting Alspen, $320 \mathrm{~km} / \mathrm{hr}$; DVM, 10 min LWC, $1.0 \mathrm{gm} / \mathrm{m}^{3}$.

\begin{tabular}{|c|c|c|}
\hline NSTRUNMT & 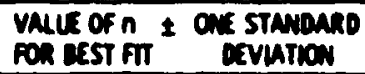 & $\begin{array}{l}\text { minimat o } \\
\text { sumins }\end{array}$ \\
\hline $\begin{array}{l}\text { A. REFATEO SPRAY } \\
\text { AND AINSFEO }\end{array}$ & & \\
\hline FSSP I & $n \cdot 22 \pm .1$ & 7 \\
\hline ASSP I & $1.51 \div .60$ & 3 \\
\hline ASSP 3 & $25 * .5$ & 4 \\
\hline ASSP 4 & $28 \pm .2$ & 3 \\
\hline $\begin{array}{l}\text { D. REFEATEO SPRAY. } \\
\text { VARED ARS FIEDO }\end{array}$ & & \\
\hline FSSP I & $n=1.39 \pm .1$ & 14 \\
\hline ASSP I & $1.61 \div .1$ & 12 \\
\hline ASSP 2 & $162 \pm .1$ & 7 \\
\hline ASSP 3 & $273 \div .6$ & $\boldsymbol{I I}$ \\
\hline ASSP 4 & $1.91 \times .1$ & 10 \\
\hline
\end{tabular}

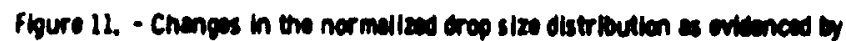

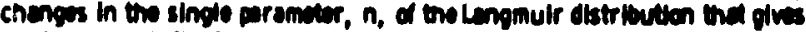

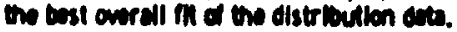


ORIGINAL PAE: :O

OF PCOR Qunlitry
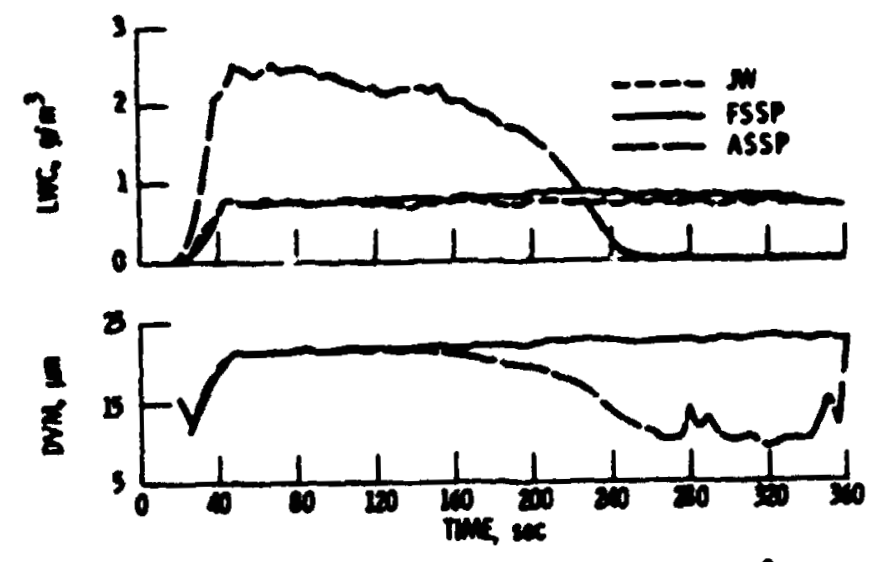

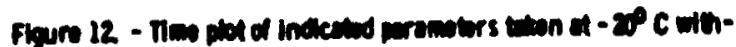
cut stann bise wrox. 